\title{
Hydrogen Permeation of Ni-Nb-Zr Metallic Glasses in a Supercooled Liquid State
}

\author{
Shin-ichi Yamaura, Shuhei Nakata, Hisamichi Kimura and Akihisa Inoue \\ Institute for Materials Research, Tohoku University, Sendai 980-8577, Japan
}

In this study, the hydrogen permeation in the supercooled liquid state for $\mathrm{Ni}_{65} \mathrm{Nb}_{25} \mathrm{Zr}_{10}, \mathrm{Ni}_{60} \mathrm{Nb}_{20} \mathrm{Zr}_{20}$ and $\mathrm{Ni}_{55} \mathrm{Nb}_{15} \mathrm{Zr}_{30}$ metallic glasses was investigated in conjunction with the discussion on the effect of hydrogen diffusion on hydrogen permeation. The hydrogen permeation of the $\mathrm{Ni}_{65} \mathrm{Nb}_{25} \mathrm{Zr}_{10}$ and $\mathrm{Ni}_{60} \mathrm{Nb}_{20} \mathrm{Zr}_{20}$ metallic glasses increases significantly by the transition from the glassy solid state to the supercooled liquid state. The temperature at which this significant increase in hydrogen permeation appears is much lower than $T_{\mathrm{g}}$ and is in correspondence with the onset temperature of the endothermic reaction relating to the glass transition. Moreover, it was found that the hydrogen permeation in the glassy phase was larger than that in the corresponding crystalline one. The contribution of hydrogen diffusion and solution to permeation is discussed in detail. [doi:10.2320/matertrans.47.2991]

(Received July 3, 2006; Accepted October 6, 2006; Published December 15, 2006)

Keywords: metallic glass, melt-spinning, supercooled liquid, glass transition, permeation

\section{Introduction}

A metallic glass is categorized as a sub-group of amorphous alloys having a significantly large supercooled liquid region just below the crystallization temperature, $T_{\mathrm{x}}$. In the end of 1980's, Inoue et al. invested the Mg-Ni-La, ${ }^{1)}$ $\mathrm{La}-\mathrm{Al}-(\mathrm{Co}, \mathrm{Ni}, \mathrm{Cu})^{2)}$ and $\mathrm{Zr}-\mathrm{Al}-(\mathrm{Ni}, \mathrm{Cu})^{3)}$ metallic glasses. These metallic glasses show the distinct glass transition $\left(T_{\mathrm{g}}\right)$ and a subsequent large supercooled liquid region of $\Delta T_{\mathrm{x}}=$ 50-100 K $\left(=T_{\mathrm{x}}-T_{\mathrm{g}}\right)$ just below $T_{\mathrm{x}}$. In the supercooled liquid region, component atoms can move easily, resulting that the liquid is in the inertially equilibrium relaxation state and is structurally stabilized. So, the supercooled liquid which is continuously cooled down to the temperature below the melting temperature, $T_{\mathrm{m}}$, has high resistance to crystallization, resulting that we can produce the bulky metallic glass ingots due to the suppression of rapid crystallization even at low cooling rates. ${ }^{4)}$

Amorphous/glassy alloys have various useful properties, for example, excellent mechanical strength, ${ }^{5)}$ excellent softmagnetic properties ${ }^{6)}$ and high corrosion resistance, ${ }^{7)}$ comparing to crystalline alloys.

Since metallic glasses include large amounts of elements having high affinity to hydrogen such as $\mathrm{Zr}, \mathrm{Pd}$ and $\mathrm{Ti}$, it is interesting to study the hydrogen-related properties of those metallic glasses. In particular, there are many reports on hydrogen storage capacity ${ }^{8,9)}$ and change of amorphous structure due to hydrogen. ${ }^{10,11)}$

Ismail et al. reported that the supercooled liquid area, $\Delta T_{\mathrm{x}}$, of the hydrogen-absorbed $\mathrm{Zr}-\mathrm{Al}-\mathrm{Ni}-\mathrm{Cu}$ metallic glasses became narrower with increasing hydrogen concentration and then finally disappeared and that the $\mathrm{Zr}$ hydrides and the $\mathrm{Cu}$-rich phase precipitated by crystallization. ${ }^{12}$ Li et al. reported that the hydrogen absorption rate of the $\mathrm{Zr}-\mathrm{Al}-\mathrm{Ni}$ metallic glasses significantly increased at above $T_{\mathrm{g}}(=715 \mathrm{~K})$ and that the $T_{\mathrm{g}}$ and $T_{\mathrm{x}}$ of the alloys decreased by hydrogen absorption. ${ }^{13)}$

Recently, hydrogen separation by using metallic membranes is in the limelight as a potential mass-production technique with low cost and low energy consumption for the coming fuel cell powered society. In general, the atomic densities of the amorphous and glassy alloys are considerably lower than the crystalline ones. This is due to larger free volumes in the amorphous and glassy alloys than in the crystalline ones. We expected that the large free volumes in the amorphous and glassy alloys could lead to high hydrogen diffusivity, resulting in excellent hydrogen permeability.

Hydrogen permeation of various amorphous alloys was already reported by many research groups. ${ }^{14-16)}$ For example, Liu et al. investigated the hydrogen permeation and the ethanol conversion efficiency of the Ni-P amorphous membranes. ${ }^{14)}$ Besides, Evard et al. reported that the permeation of the Fe-Ni-Si-B-C-P amorphous alloys showed the maximum value at around $473 \mathrm{~K}$ while that of the corresponding crystalline ones increased with temperature. ${ }^{15)}$ Hara et al. also reported high permselectivity of the $\mathrm{Ni}-\mathrm{Zr}$ amorphous alloys. ${ }^{16)}$ Furthermore, many investigations on hydrogen solubility and diffusivity in amorphous alloys were already performed and reported by many researchers particularly by Kirchheim et al. ${ }^{17)}$

We developed the $\mathrm{Ni}-\mathrm{Nb}-\mathrm{Zr}$ amorphous alloys and previously reported that the hydrogen permeability of the melt-spun $\left(\mathrm{Ni}_{0.6} \mathrm{Nb}_{0.4}\right)_{70} \mathrm{Zr}_{30}$ amorphous alloy was as high as the Pd-based alloy. ${ }^{18)}$ In the Ni-Nb-Zr ternary system, the $\mathrm{Ni}_{60} \mathrm{Nb}_{20} \mathrm{Zr}_{20}$ possesses the largest supercooled liquid region of about $\Delta T_{\mathrm{x}}=50 \mathrm{~K}^{1{ }^{19)}}$ It can be expected that the hydrogen diffusivity in the supercooled liquid is higher than that in the glassy solid phase because the hydrogen absorption rate increases significantly in the supercooled liquid state of metallic glasses as previously reported by Li et al. ${ }^{13)}$

It is important to study the hydrogen solubility and diffusivity in the alloys because those two factors can affect hydrogen permeability in the alloys. It is not easy to develop new membrane materials because too much hydrogen solution should result in severe embrittlement of the membranes. If we can improve hydrogen permeability by investigating the hydrogen permeation and diffusion in the supercooled liquid state, such knowledge will indeed lead to the development of new membrane materials having high hydrogen permeability owing to high hydrogen diffusivity rather than 
the increase in the hydrogen solubility. Moreover, it is important to investigate thermal stability and the precipitated phase of the $\mathrm{Ni}-\mathrm{Nb}-\mathrm{Zr}$ metallic glasses in a $\mathrm{H}_{2}$ atmosphere since they cannot escape from crystallization in the case of using them at high temperature. So the objective of this work is to investigate the hydrogen permeation behavior and thermal stability of the $\mathrm{Ni}_{60} \mathrm{Nb}_{20} \mathrm{Zr}_{20}$ metallic glass at elevated temperature.

\section{Experimental Procedure}

Alloy ingots of the $\mathrm{Ni}_{65} \mathrm{Nb}_{25} \mathrm{Zr}_{10}, \mathrm{Ni}_{60} \mathrm{Nb}_{20} \mathrm{Zr}_{20}$ and $\mathrm{Ni}_{55} \mathrm{Nb}_{15} \mathrm{Zr}_{30}$ were prepared by arc-melting the mixture of pure metals in an Ar atmosphere. Melt-spun ribbons were produced from those mother alloys by the single-roller meltspinning technique in an $\mathrm{Ar}$ atmosphere. The ribbons were about $10 \mathrm{~mm}$ wide and about $40 \mu \mathrm{m}$ thick. Amorphicity and thermal stability of melt-spun ribbon specimens were examined by X-ray diffractometry $(\mathrm{CuK} \alpha, 40 \mathrm{kV}, 30 \mathrm{~mA}$, hereafter denoted as XRD, RIGAKU RAD-B model,) and differential scanning calorimetry at a heating rate of $0.33 \mathrm{~K} / \mathrm{s}$ in an Ar atmosphere (DSC, Seiko Instruments Incorporated DSC-6300 model) and also in a $\mathrm{H}_{2}$ one (RIGAKU DSC8230HP model). The purity of $\mathrm{H}_{2}$ gas used in this study was $99.99999 \%$ (7Nup).

Palladium thin film was deposited on both sides of specimens by the sputtering technique as an active catalyst for promoting hydrogen dissociation and recombination during permeation. Before the Pd deposition, the surface of the specimens was mechanically polished with Emery papers. The thickness of the Pd deposition was about $0.1 \mu \mathrm{m}$. Hydrogen permeation measurements were performed with a conventional gas-permeation technique. Membrane samples were mounted in the gas-permeation cell at the temperature up to $T_{\mathrm{x}}$ by using an infrared ray lamp heater. Pure hydrogen gas was introduced to one side of a membrane and then the flow rate of effluent hydrogen gas from the other side (permeate side) was measured by a mass flow meter. Pure He gas was introduced to the sample cell and then the cell was evacuated by a rotary pump. This procedure was repeated five times before heating. The sample membranes were heated at the heating rate of $0.33 \mathrm{~K} / \mathrm{s}$ in vacuum. Soon after the samples were heated at up to a certain temperature, pure $\mathrm{H}_{2}$ was introduced to the sample cell. It took a few minutes to control the pressure difference and to start the flux measurement.

Furthermore, the hydrogenation rate of the samples was examined by a conventional gas volumetric method. The time-temperature-transition (TTT) diagrams of the sample alloys were also obtained by the DSC measurements (in a $\mathrm{H}_{2}$ atmosphere) and by the annealing of samples in evacuated quartz tubes. From the DSC curves, the starting and the ending temperatures $\left(T_{\mathrm{x}}{ }^{\text {start }}\right.$ and $\left.T_{\mathrm{x}}{ }^{\text {end }}\right)$ for crystallization were measured and plotted as a TTT diagram.

\section{Results \& Discussion}

\subsection{Thermal stability}

Figure 1 shows the XRD patterns of the melt-spun $\mathrm{Ni}_{65} \mathrm{Nb}_{25} \mathrm{Zr}_{10}, \mathrm{Ni}_{60} \mathrm{Nb}_{20} \mathrm{Zr}_{20}$ and $\mathrm{Ni}_{55} \mathrm{Nb}_{15} \mathrm{Zr}_{30}$ alloys. No

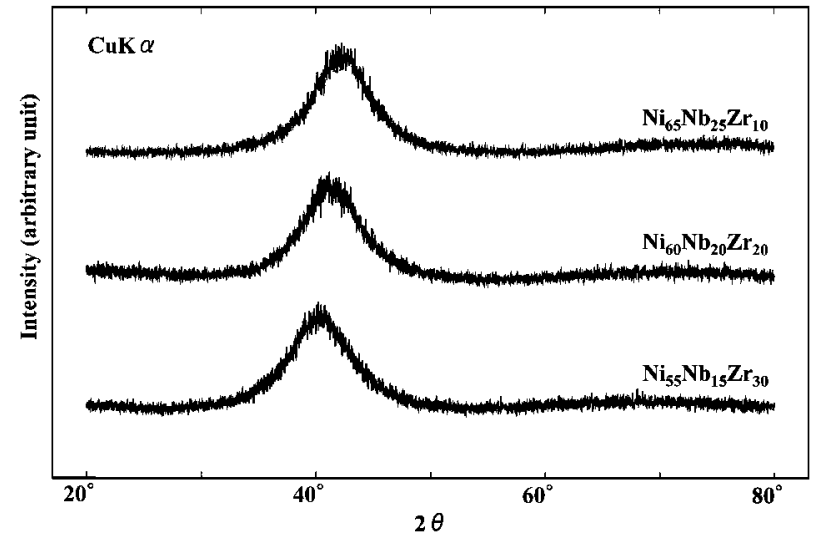

Fig. 1 The XRD patterns of the melt-spun $\mathrm{Ni}_{65} \mathrm{Nb}_{25} \mathrm{Zr}_{10}, \mathrm{Ni}_{60} \mathrm{Nb}_{20} \mathrm{Zr}_{20}$ and $\mathrm{Ni}_{55} \mathrm{Nb}_{15} \mathrm{Zr}_{30}$ alloys.

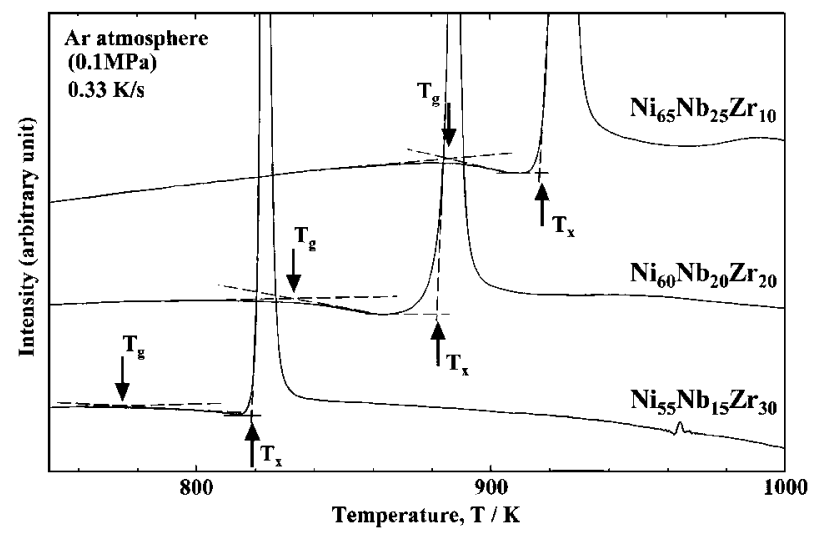

Fig. 2 The DSC curves of the glassy samples measured in an Ar atmosphere.

sharp distinct peaks are observed in the $2 \theta$ range of $20-80^{\circ}$, indicating that all alloys possess a single glassy phase.

The DSC curves of the glassy samples obtained in an Ar atmosphere are shown in Fig. 2. The endothermic broad peak indicating the appearance of the supercooled liquid state between $T_{\mathrm{g}}$ and $T_{\mathrm{x}}$ was observed just below the subsequent exothermic crystallization peak in all the three samples. From the DSC curves, it was found that $T_{\mathrm{g}}$ and $T_{\mathrm{x}}$ decreased with increasing $\mathrm{Zr}$ content in the alloys. The $\mathrm{Ni}_{60} \mathrm{Nb}_{20} \mathrm{Zr}_{20}$ alloy shows the largest supercooled liquid region of $\Delta T_{\mathrm{x}}=50 \mathrm{~K}$ among the three alloys prepared in this study.

Figure 3 shows the DSC curves of the samples measured in a $\mathrm{H}_{2}$ atmosphere. Hydrogen pressure inside the chamber was $0.5 \mathrm{MPa}$ during the measurements. For these measurements, the sample membranes with the Pd thin deposition were used. Since it was impossible to heat the samples up to the temperature higher than $873 \mathrm{~K}$ with the $\mathrm{H}_{2}$-DSC equipment used in this study, we did not observe the complete crystallization behavior of the $\mathrm{Ni}_{65} \mathrm{Nb}_{25} \mathrm{Zr}_{10}$ metallic glass having the highest $T_{\mathrm{x}}$ among the samples. Table 1 summarizes $T_{\mathrm{g}}$ and $T_{\mathrm{x}}$ obtained in this work. It was found that those metallic glasses become thermally unstable in a $\mathrm{H}_{2}$ atmosphere rather than in an $\mathrm{Ar}$ one. Besides, a large broad exothermic peak appears at around room temperature in Fig. 3, indicating that the $\mathrm{Ni}-\mathrm{Nb}-\mathrm{Zr}$ metallic glasses prepared 


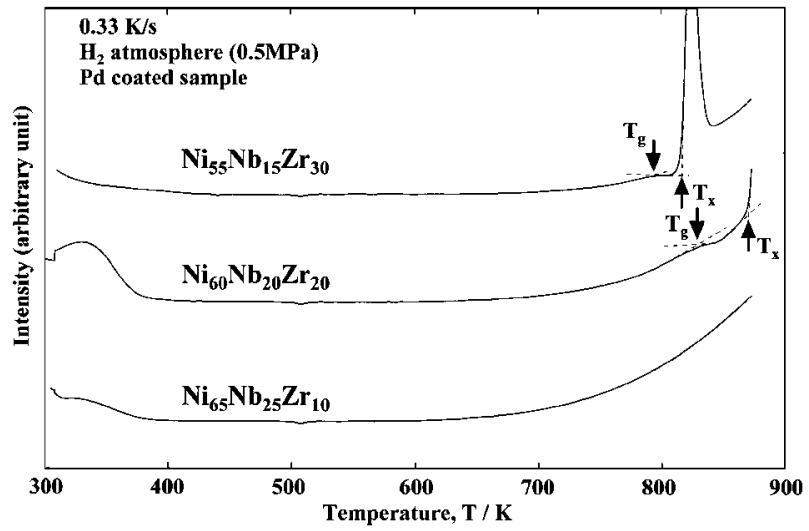

Fig. 3 The DSC curves of the glassy samples measured in a $\mathrm{H}_{2}$ atmosphere.

in this study can absorb hydrogen easily at low temperatures. Then after the appearance of the exothermic broad peak at low temperature, the DSC lines become lower than the baseline, indicating a large broad endothermic region of hydrogen desorption and also the small endothermic peak at around $510 \mathrm{~K}$ corresponding to hydrogen desorption from $\mathrm{Pd}$ films. This observation would agree with many previous results reported that the hydrogen solubility of amorphous alloys generally increases with decreasing temperature, ${ }^{20)}$ and for example, corresponds to the previously reported behavior of the $\left(\mathrm{Ni}_{0.6} \mathrm{Nb}_{0.4}\right)_{70} \mathrm{Zr}_{30}$ amorphous alloy having the broad large endothermic region in the range of 573$773 \mathrm{~K}$ in the DSC curve. ${ }^{21)}$

\subsection{Hydrogen permeability}

Figure 4 shows the results of the permeation tests, showing the initial hydrogen permeability of the $\mathrm{Ni}_{60} \mathrm{Nb}_{20} \mathrm{Zr}_{20}$ metallic glass at different temperatures. We used the samples with the Pd deposition on both sides of them. As shown in this figure, it was found that the hydrogen permeabilities obtained at 823 and $843 \mathrm{~K}$ were much larger than those obtained at lower temperatures. The $T_{\mathrm{g}}$ of this alloy obtained in an $\mathrm{Ar}$ atmosphere is $833 \mathrm{~K}$. The permeabilities obtained at 823 and $843 \mathrm{~K}$ decreased rapidly in a few hundred seconds whereas they did not decrease when measured at around $773 \mathrm{~K}$. The crystallization would lead to such a severe rapid degradation of the permeability at 823 and $843 \mathrm{~K}$. In general, since the supercooled liquid state of the metallic glass cannot be kept stably for a long time, the crystallization would occur in a certain time even at the temperature lower than $T_{\mathrm{x}}$. In order to know the thermal stability of this metallic glass in more detail, the TTT diagram was made.

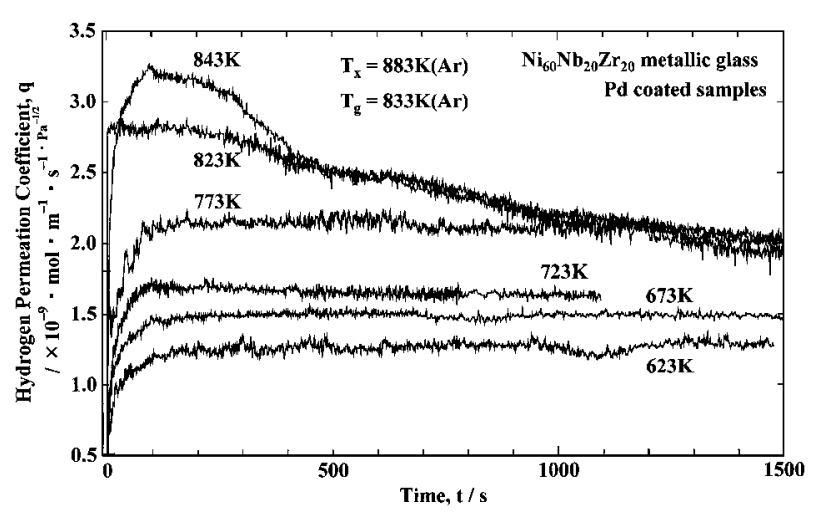

Fig. 4 The results of the permeation tests, showing the initial hydrogen permeability of the $\mathrm{Ni}_{60} \mathrm{Nb}_{20} \mathrm{Zr}_{20}$ metallic glass at different temperatures.

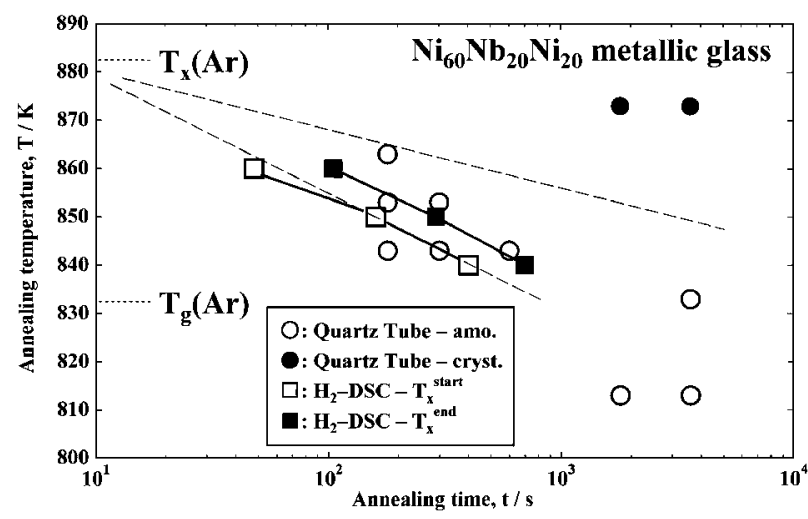

Fig. 5 The TTT diagrams of the glassy-to-crystalline phase transformation; (a) the diagram obtained from the short-time annealing of the alloy in evacuated quartz tubes and (b) from the $\mathrm{H}_{2}$-DSC measurements.

Figure 5 shows the TTT diagrams of the glassy-tocrystalline phase transformation. Open and solid circles indicate the data obtained from the short-time annealing of the alloy in evacuated quartz tubes. Open and solid rectangles indicate the data obtained from the $\mathrm{H}_{2}$-DSC measurements. An exothermic peak, corresponding to the crystallization, would appear in the measurements during isothermal annealing by using the DSC equipment. The starting and the ending temperatures of the exothermic peak are denoted as $T_{\mathrm{x}}$ start and $T_{\mathrm{x}}{ }^{\text {end }}$, respectively. As clearly shown in the figure, the metallic glass started to crystallize in a few to ten minutes at the temperature above $T_{\mathrm{g}}$. The glassy single phase was kept after annealing for $1 \mathrm{~h}$ at $813 \mathrm{~K}$ much lower than $T_{\mathrm{g}}$ in vacuum. In this figure, it was clearly shown that the crystallization of the supercooled liquid was promoted by hydrogen, resulting in the decrease in $T_{\mathrm{x}}$. This is the reason

Table 1 Glass transition temperature, $T_{\mathrm{g}}$, crystallization temperature, $T_{\mathrm{x}}$ and supercooled liquid region, $\Delta T_{\mathrm{x}}$ of the melt-spun Ni-Nb-Zr glassy alloys measured at the heating rate of $0.33 \mathrm{~K} / \mathrm{s}$ in an $\mathrm{Ar}$ atmosphere and a $\mathrm{H}_{2}$ one.

\begin{tabular}{|c|c|c|c|c|c|c|}
\hline \multirow{2}{*}{$\begin{array}{c}\text { Alloy } \\
\text { compositions }\end{array}$} & \multicolumn{3}{|c|}{ Ar atmosphere (0.1 MPa) } & \multicolumn{3}{|c|}{$\mathrm{H}_{2}$ atmosphere $(0.5 \mathrm{MPa})$} \\
\hline & $T_{\mathrm{g}}[\mathrm{K}]$ & $T_{\mathrm{x}}[\mathrm{K}]$ & $\Delta T_{\mathrm{x}}\left(=T_{\mathrm{g}}-T_{\mathrm{x}}\right)[\mathrm{K}]$ & $T_{\mathrm{g}}[\mathrm{K}]$ & $T_{\mathrm{x}}[\mathrm{K}]$ & $\Delta T_{\mathrm{x}}\left(=T_{\mathrm{g}}-T_{\mathrm{x}}\right)[\mathrm{K}]$ \\
\hline $\mathrm{Ni}_{65} \mathrm{Nb}_{25} \mathrm{Zr}_{10}$ & 887 & 918 & 31 & - & - & - \\
\hline $\mathrm{Ni}_{55} \mathrm{Nb}_{15} \mathrm{Zr}_{30}$ & 774 & 819 & 45 & 795 & 818 & 23 \\
\hline
\end{tabular}



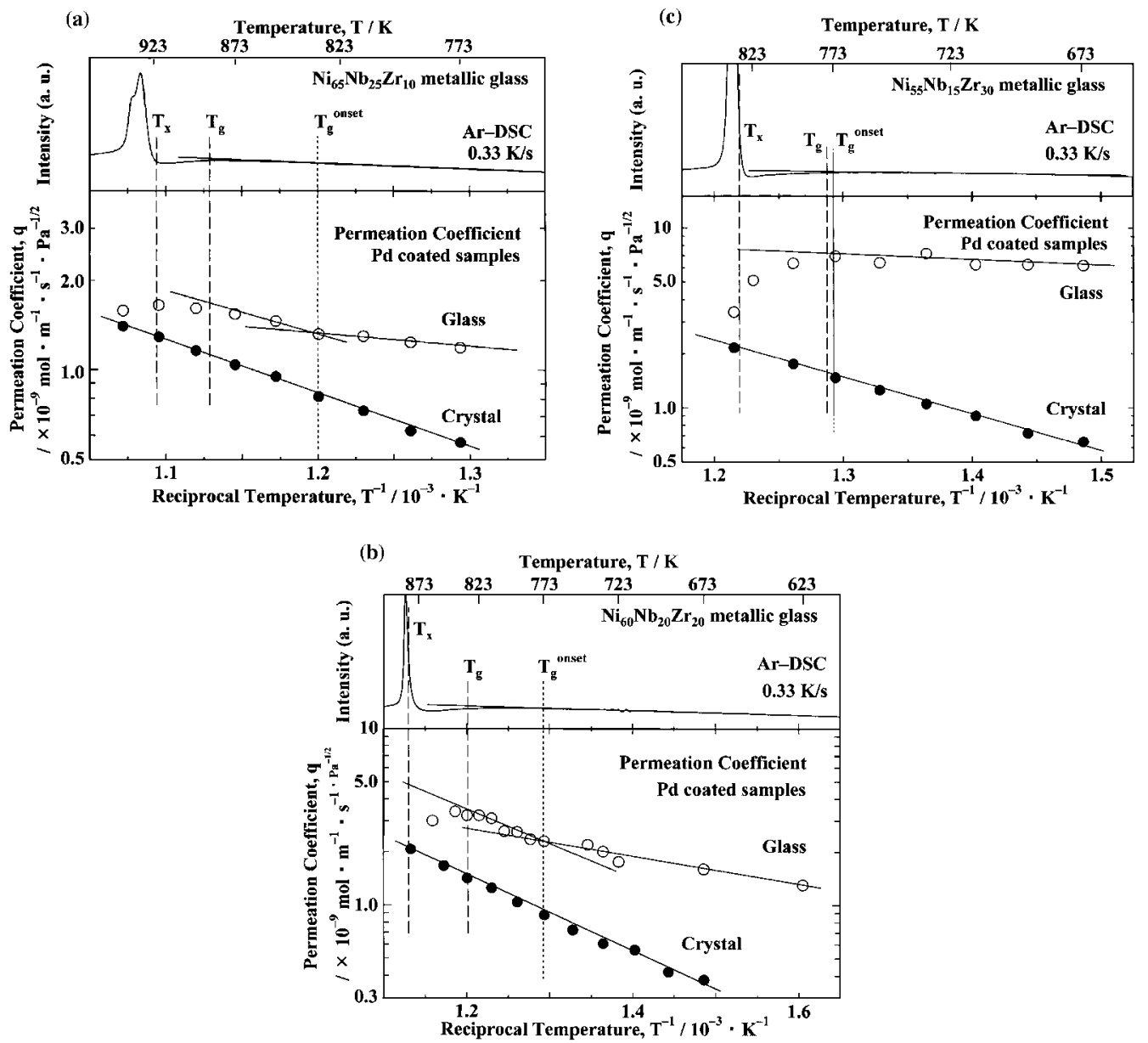

Fig. 6 The maximum hydrogen permeability obtained from each permeation measurement.

why the permeation decreases significantly in a few minutes at around $T_{\mathrm{g}}$.

The maximum hydrogen permeability obtained from each permeation measurement shown in Fig. 4 was plotted in Fig. 6. A new sample was used in each measurement. As a reference, the DSC curve of each alloy obtained in an Ar atmosphere was superimposed on the plot. For the measurement of the permeation behavior of the crystalline ones, the samples were heated over $T_{\mathrm{x}}$ at first and then the permeation was measured during continuous cooling down. Figures 6(a), (b) and (c) indicate the measurement results for the $\mathrm{Ni}_{65} \mathrm{Nb}_{25} \mathrm{Zr}_{10}$, the $\mathrm{Ni}_{60} \mathrm{Nb}_{20} \mathrm{Zr}_{20}$ and the $\mathrm{Ni}_{55} \mathrm{Nb}_{15} \mathrm{Zr}_{30}$ metallic glasses, respectively. As shown in the figures, the permeation of the crystalline samples increased with increasing temperature monotonously. The permeation of the $\mathrm{Ni}_{65} \mathrm{Nb}_{25} \mathrm{Zr}_{10}$ and the $\mathrm{Ni}_{60} \mathrm{Nb}_{20} \mathrm{Zr}_{20}$ metallic glasses also increased with increasing temperature. Besides, it was also found that the inclination of hydrogen permeation of those two metallic glasses significantly increased at much lower temperature than $T_{\mathrm{g}}$. This temperature may correspond to the onset temperature of the endothermic broad peak of glass transition, $T_{\mathrm{g}}$ onset in the DSC curve. This significant increase of the inclination of hydrogen permeation at $T_{\mathrm{g}}{ }^{\text {onset }}$ may be due to the increase in hydrogen diffusivity in the supercooled liquid phase appearing with endothermic reaction in the DSC curve. Since the thermal stability of the $\mathrm{Ni}_{55} \mathrm{Nb}_{15} \mathrm{Zr}_{30}$ metallic glass is the lowest among the three alloys, the crystallization already occur before we start the measurements at the temperature higher than $800 \mathrm{~K}$. Therefore, no significant increase in the inclination was observed in this alloy.

As for the conventional diffusion, for example, selfdiffusion of constituent atoms in the $\mathrm{Zr}-\mathrm{Al}-\mathrm{Ni}-\mathrm{Cu}-\mathrm{Be}$ and $\mathrm{Pd}-\mathrm{Cu}-\mathrm{Ni}-\mathrm{P}$ metallic glasses, ${ }^{22,23)}$ it was reported that the diffusion coefficient increases significantly just at the temperature higher than $T_{\mathrm{g}}$. Knorr et al. investigated the self-diffusion in the supercooled liquid state of the $\mathrm{Zr}-\mathrm{Ti}-\mathrm{Cu}-$ $\mathrm{Ni}$-Be metallic glass and proposed the collective diffusion mechanism mediated by vacancy-like thermal defects. ${ }^{24)}$ Besides, Fielitz et al. also investigated the diffusivities of impurities in the $\mathrm{Zr}-\mathrm{Ti}-\mathrm{Cu}-\mathrm{Ni}-\mathrm{Be}$ metallic glass and concluded that the diffusion mechanism could be changed just at the temperature around $T_{\mathrm{g}}$ and that the cooperative motion of atoms improves predominantly the diffusivity in the supercooled liquid state. ${ }^{25)}$ However, hydrogen permeation starts to increase significantly at the temperature below $T_{\mathrm{g}}$ as shown in this study. It is known that some physical parameters of the metallic glass start to change at the temperature much lower than $T_{\mathrm{g}}$. For example, the flow stress of the metallic glass decreases at the temperature much lower than $T_{\mathrm{g}}{ }^{26}$ ) Since hydrogen atoms are the smallest among the elements, hydrogen diffusion can be affected sensitively by the local atomic structure change even at the temperature below $T_{\mathrm{g}}$, resulting that hydrogen diffusion 
(a)

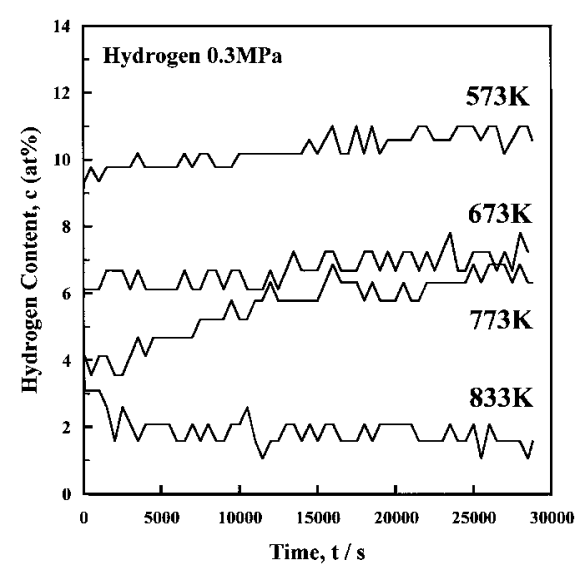

(b)

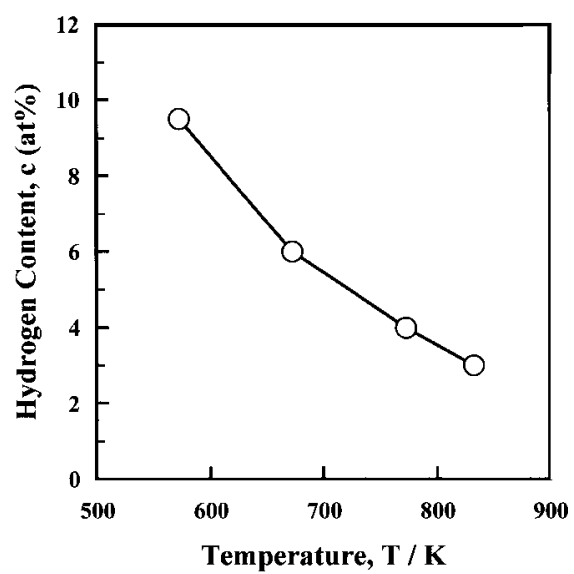

Fig. 7 The temperature-dependence of hydrogen absorption as a function of measurement time (a) and the initial absorption content (b) of the $\mathrm{Ni}_{60} \mathrm{Nb}_{20} \mathrm{Zr}_{20}$ metallic glass.

becomes easily as soon as the endothermic reaction starts. As clearly shown in the figure, hydrogen permeation increases significantly at the temperature lower than $T_{\mathrm{g}}$ by more than $50 \mathrm{~K}$. Moreover, it was found that the hydrogen permeation in the glassy phase was larger than that in the corresponding crystalline one.

\subsection{Hydrogen Absorption Rate}

It is necessary to measure the hydrogen solubility for discussing hydrogen permeation of the alloys. Figure 7 shows (a) the temperature-dependence of hydrogen absorption as a function of measurement time and (b) the initial absorption content of the $\mathrm{Ni}_{60} \mathrm{Nb}_{20} \mathrm{Zr}_{20}$ metallic glass. In these measurements, the samples with $\mathrm{Pd}$ thin deposition were used. From these figures, it was clearly found that the hydrogen solubility decreased with temperature in this glassy alloy. Similar tendency that the hydrogen storage capacity of the $\mathrm{Ni}-\mathrm{Zr}$ amorphous alloy decreased with temperature was previously reported by Aoki et al. ${ }^{20)}$ The hydrogen solubility decreased significantly in initial $2.5 \mathrm{ks}$ at $833 \mathrm{~K}$ probably due to severe crystallization as shown in Fig. 7(a). Figure 7(b) indicates the initial increase of hydrogen solubility magnified from Fig. 7(a). In general, the melt of metals can absorb larger amount of hydrogen at above the melting temperature, $T_{\mathrm{m}}$, than the corresponding crystalline solid state of the metals. However, as shown in Fig. 7(b), the supercooled liquid of the alloy obtained at $833 \mathrm{~K}$ did not absorb hydrogen so much. Therefore, it can be concluded that the increase in hydrogen permeation in the supercooled liquid state observed in Fig. 6 is caused predominantly by the significant increase in hydrogen diffusivity in the supercooled liquid state.

Figure 8 shows the XRD patterns of the samples used for the solubility measurements for $8 \mathrm{~h}$. A glassy single phase in the samples is kept with the surface Pd thin film layer even after the solubility measurements for $8 \mathrm{~h}$ at $573-773 \mathrm{~K}$. The Pd peak height becomes smaller, indicating the diffusion of $\mathrm{Pd}$ into the sample alloy at $773 \mathrm{~K}$. Then many diffraction peaks appeared in the sample after the measurement at $833 \mathrm{~K}$. The predominant phase may be regarded as the $\mathrm{Ni}_{10} \mathrm{Zr}_{7}$ and $\mathrm{Ni}_{11} \mathrm{Zr}_{9}$. The $\mathrm{ZrH}_{2}$ phase whose strongest

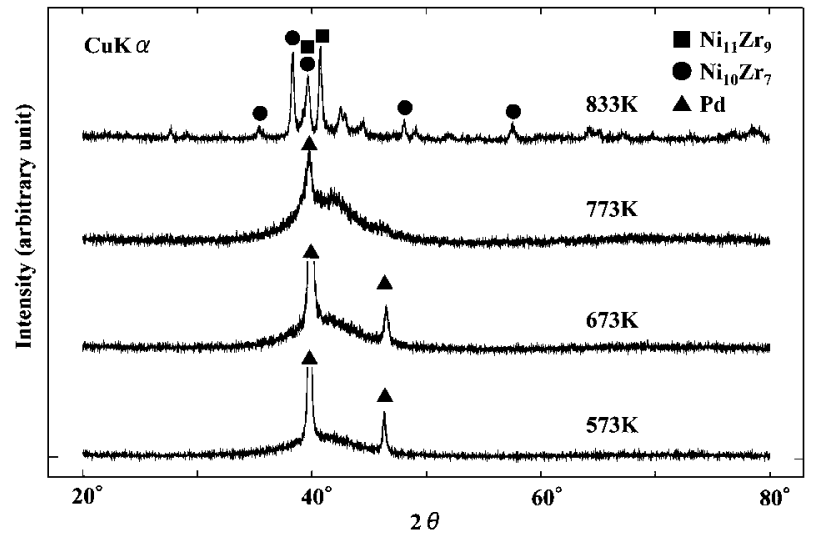

Fig. 8 The XRD patterns of the samples used for the solubility measurements for $8 \mathrm{~h}$.

diffraction peak should appear at around $2 \theta=32.4^{\circ}$ was not observed clearly.

In general, hydrogen permeate flux is proportional to the hydrogen solubility and diffusivity and is inversely proportional to the thickness of the sample. Therefore, the increase in the hydrogen solubility and diffusivity and the decrease in the sample thickness are preferable for the increase in the hydrogen permeation. As shown in Fig. 6, the hydrogen permeation increases with temperature. Furthermore, it increases more significantly in the supercooled liquid state. However, the hydrogen solubility decreases with increasing temperature as shown in Fig. 7. Therefore, the reason why the hydrogen permeation of the alloy in the supercooled liquid state increases with increasing temperature is because the increase in hydrogen diffusivity with temperature exceeds the decrease in hydrogen solubility. In particular, in the supercooled liquid state, the distinct increase in hydrogen diffusivity leads to the significant increase in the hydrogen permeation. Moreover, the hydrogen permeation starts to increase at around the onset temperature, $T_{\mathrm{g}}{ }^{\text {onset }}$, of the endothermic broad peak corresponding to the glass transition as seen in Fig. 6. From this observation, it can be understood that the hydrogen diffusivity starts to increase significantly at $T_{\mathrm{g}}{ }^{\text {onset }}$, which is much lower than $T_{\mathrm{g}}$. For example, the free 
volume in the glass decreases with temperature then reached the minimum at below $T_{\mathrm{g}}$ and finally increases with temperature. This free volume relating to the local atomic structure may affect the hydrogen diffusivity. ${ }^{27)}$ This may be one of the reasons for the significant increase in the hydrogen permeation even at below $T_{\mathrm{g}}$.

As for the previous research and development of hydrogen permeable membranes, it was impossible to suppress the hydrogen embrittlement because the alloy design for high hydrogen solubility with the elements having high hydrogen affinity had been considered. In the future, it is important to develop a new membrane alloy with high hydrogen diffusivity and medium hydrogen solubility in order to suppress the severe hydrogen embrittlement. Unfortunately, it is impossible to use the metallic glass as a membrane in the supercooled liquid state due to the crystallization. Nowadays, the $\mathrm{Nb}$ and $\mathrm{V}$ metals having the bcc structure in which hydrogen can diffuse relatively faster than in the fcc structure, have been adopted as the base metal of the new membrane alloys. As a new alloy design, we can suggest that other bcc metals showing high hydrogen diffusivity and low hydrogen solubility such as Fe should be focused for a base metal and that the medium hydrogen solubility should be given to such bcc metals by alloying with elements having high hydrogen affinity, resulting that the developed alloys might show the high hydrogen permeability with high hydrogen diffusivity and medium solubility. This is one of the potential suggestions derived from this work. In this study, we demonstrated a possibility that the hydrogen permeation can increase significantly with increasing diffusivity and with decreasing solubility through the insight of hydrogen permeation in the supercooled liquid of the metallic glasses. We suggest that it is important to develop a new membrane alloy with high hydrogen diffusivity.

\section{Summary}

In this study, we measured the hydrogen permeation of the $\mathrm{Ni}_{65} \mathrm{Nb}_{25} \mathrm{Zr}_{10}, \quad \mathrm{Ni}_{60} \mathrm{Nb}_{20} \mathrm{Zr}_{20}$ and $\mathrm{Ni}_{55} \mathrm{Nb}_{15} \mathrm{Zr}_{30}$ metallic glasses in the supercooled liquid state and discussed the effect of hydrogen diffusion on hydrogen permeation in the supercooled liquid state.

(1) From the DSC measurements in an Ar atmosphere, it was found that all the alloys prepared in this study possessed a large supercooled liquid region. The $\mathrm{Ni}_{60} \mathrm{Nb}_{20} \mathrm{Zr}_{20}$ metallic glass shows the largest $\Delta T_{\mathrm{x}}$ of about $50 \mathrm{~K}$. From the DSC measurements in a $\mathrm{H}_{2}$ atmosphere, $T_{\mathrm{x}}$ falled down, resulting that the $\Delta T_{\mathrm{x}}$ became narrower than that in an Ar atmosphere. It is found that hydrogen can promote the unstabilization/ crystallization of the supercooled liquid as shown in TTT diagrams.

(2) The hydrogen permeation of the $\mathrm{Ni}_{65} \mathrm{Nb}_{25} \mathrm{Zr}_{10}$ and $\mathrm{Ni}_{60} \mathrm{Nb}_{20} \mathrm{Zr}_{20}$ metallic glasses increases significantly by the transition from the glassy solid state to the supercooled liquid state. The temperature at which this significant increase in hydrogen permeation starts is much lower than $T_{\mathrm{g}}$ and is in correspondence with the onset temperature of the endothermic reaction, $T_{\mathrm{g}}{ }^{\text {onset }}$, relating to the glass transition.

(3) The $\mathrm{Ni}_{60} \mathrm{Nb}_{20} \mathrm{Zr}_{20}$ metallic glass possesses a single glassy phase even after hydrogenation for $8 \mathrm{~h}$ at below $773 \mathrm{~K}$. However, the crystallization occurs after hydrogenation at above $T_{\mathrm{g}}(=833 \mathrm{~K})$. The predominant crystalline phase is the $\mathrm{Zr}-\mathrm{Ni}$. The $\mathrm{ZrH}_{2}$ phase was not observed clearly.

\section{REFERENCES}

1) A. Inoue, M. Kohinata, A. P. Tsai and T. Masumoto: Mater. Trans., JIM 30 (1990) 378-381.

2) A. Inoue, T. Zhang and T. Masumoto: Mater. Trans., JIM 30 (1989) 965-972.

3) A. Inoue, T. Zhang and T. Masumoto: Mater. Trans., JIM 31 (1990) $177-183$.

4) A. Inoue, N. Nishiyama and T. Matsuda: Mater. Trans., JIM 37 (1996) 181-184.

5) A. Inoue, B. Shen, H. Koshiba, H. Kato and A. R. Yavari: Nat. Mater. 2 (2003) 661-663.

6) B. Shen, H. M. Kimura, A. Inoue and T. Mizushima: Mater. Trans. 42 (2001) 660-663.

7) S. J. Pang, T. Zhang, H. M. Kimura, K. Asami and A. Inoue: Mater. Trans. 41 (2000) 1490-1494.

8) R. Kirchheim: Acta Metall. 30 (1982) 1059-1068.

9) X. Q. Guo, D. V. Louzguine, S. Yamaura, L. Q. Ma, W. Sun, M. Hasegawa and A. Inoue: Mater. Sci. Eng. A 338 (2002) 97-100.

10) G. G. Libowitz and A. J. Maeland: J. Less-Comm. Met. 101 (1984) 131-143.

11) K. Suzuki: J. Less-Comm. Met. 89 (1983) 183-195.

12) N. Ismail, M. Uhlemann, A. Gebert and J. Eckert: J. Alloy. Comp. 298 (2000) 146-152.

13) X. G. Li, T. Otahara, S. Takahashi, T. Shoji, H. M. Kimura and A. Inoue: J. Alloy. Comp. 297 (2000) 303-311.

14) B. S. Liu, W. D. Zhang, W. L. Dai and J. F. Deng: J. Membr. Sci. 244 (2004) 243-249.

15) E. A. Evard, A. A. Kurdumov, F. N. Berseneva and I. E. Gabis: Int. J. Hydrogen Energy 26 (2001) 457-460.

16) S. Hara, K. Sakaki, N. Itoh, H. M. Kimura, K. Asami and A. Inoue: J. Membr. Sci. 164 (2000) 289-294.

17) R. Kirchheim, T. Muetschele and W. Kieninger, H. Gleiter, R. Birringer and T. D. Koble: Mater. Sci. Eng. 99 (1988) 457-462.

18) S. Yamaura, M. Sakurai, M. Hasegawa, K. Wakoh, Y. Shimpo, M. Nishida, H. M. Kimura, E. Matsubara and A. Inoue: Acta Mater. 53 (2005) 3703-3711.

19) H. M. Kimura, A. Inoue, S. Yamaura, K. Sasamori, M. Nishida, Y. Shinpo and H. Okouchi: Mater. Trans. 44 (2003) 1167-1171.

20) K. Aoki, M. Kamachi and T. Masumoto: J. Non-Cryst. Sol. $61 \& 62$ (1984) 679-684

21) S. Yamaura, Y. Shimpo, H. Okouchi, M. Nishida, O. Kajita, H. M. Kimura and A. Inoue: Mater. Trans. 44 (2003) 1885-1890.

22) H. Ehmler, A. Heesenmann, K. Raetzke, F. Faupel and U. Geyer: Phys. Rev. Lett. 80 (1998) 4919-4922.

23) H. Nakajima: Materia Japan Inst. Metals 41 (2002) 15-19.

24) K. Knorr, M. P. Macht, K. Freitag and H. Mehrer: J. Non-Cryst. Sol. 250-252 (1999) 669-673.

25) P. Fielitz, M. P. Macht, V. Naundorf and G. Frohberg: J. Non-Cryst. Sol. 250-252 (1999) 674-678.

26) Y. Kawamura, T. Shibata, A. Inoue and T. Masumoto: Scripta Mater. 37 (1997) 431-436.

27) A. Takeuchi and A. Inoue: Mater. Trans. 43 (2002) 1205-1213. 